Куракова Татьяна Валерьевна

кандидат философских наук, доцент кафедры социологии, правоведения и работы с персоналом Кубанского государственного

технологического университета

\section{ВЗАИМОСВЯЗЬ СИСТЕМ ДОКУМЕНТООБОРОТА И ВНУТРЕННЕГО КОНТРОЛЯ ОРГАНИЗАЦИИ}

\begin{abstract}
Аннотация:
В представленной статье документ рассматривается как главный источник создания и функци онирования системы внутреннего контроля в организации, поскольку именно документ является носителем экономической и управленческой информации. Автор определяет правовые основы работы с документацией в рамках действия контрольной среды, принципы построения документооборота на разных участках деятельности, а также предлагает варианты формирования документопотоков с точки зрения их задействования в экономическом анализе. Среди ключевых принципов работы с документами обозначены своевременность, минимизация времени обработки документа, однократность регистрации и возможность использования в экономическом анализе. C позиции реализации последнего принципа автор выделяет требования к документам, а именно: содержание числовых значений в анализируемых материалах и применение сводных регистров.
\end{abstract}

Ключевые слова:

документооборот, система внутреннего контроля, документ, экономический анализ, документопотоки, контрольная среда, оценка рисков, принципы работы с документами.
Kurakova Tatyana Valeryevna

PhD, Associate Professor, Sociology, Legal Science and Human Resources Department, Kuban State Technological University

\section{THE RELATIONSHIP BETWEEN DOCUMENT MANAGEMENT AND INTERNAL CONTROL IN AN ORGANIZATION}

Summary:

A document is considered as a pivotal element in the internal control system of an organization because it contains the economic and management information. The author defines the legal framework of work management within the control environment, discusses the principles of document management in different scopes of activities and suggests ways to create document flow in terms of its application in the economic analysis. The key principles of document management include promptness, minimization of document processing time, one-time registration, usage in economic analysis. From the standpoint of the latter, the author identifies several documentation requirements such as numeric values in documents being analyzed and usage of consolidated registers.

Keywords: document management, internal control system, document, economic analysis, document flow, control environment, risk assessment, principles of document management.

Современную управленческую деятельность любой организации невозможно представить без реализации контрольных функций: управления производством, рационального использования имеющихся ресурсов и формирования их резервов, работы с персоналом и т. д. Согласно федеральному закону «О бухгалтерском учете» от 06.12.2011 г. № 402-Ф3 в России данный процесс определен как «внутренний контроль» [1]. Иными словами, внутренний контроль - это постоянный процесс, организованный руководством компании в целях получения «достаточной уверенности» в следующем:

- предприятие работает эффективно (обеспечен стабильный темп увеличения прибыли, показателей материало- и фрондоотдачи, производительности труда и т. п.);

- учреждение осуществляет деятельность в рамках действующего законодательства (налогового, административного, трудового).

В соответствии с информацией Минфина РФ № ПЗ-11/2013 «Организация и осуществление экономическим субъектом внутреннего контроля совершаемых фактов хозяйственной жизни, ведения бухгалтерского учета и составления бухгалтерской (финансовой) отчетности» выделяются следующие элементы системы внутреннего контроля (далее - СВК): контрольная среда, оценка рисков, процедуры внутреннего контроля, информация и коммуникация, оценка внутреннего контроля [2].

Остановимся подробнее на контрольной среде и оценке рисков. Первая представляет собой конкретизированный набор норм, принципов, правил, стандартов деятельности, которые определяют сущность внутреннего контроля и требования к его организации и реализации (например, федеральный закон «О бухгалтерском учете», содержащий основные положения и цели создания и функционирования системы внутреннего контроля, является элементом контрольной среды). 
Оценка рисков выступает в качестве постоянного процесса выявления и анализа рисков вероятности того, что компания в кратко- и долгосрочном периодах не будет способна достигать основных и второстепенных целей ее деятельности (в частности, рисков потенциального снижения выручки, искажения данных и т. п.). Оценка и предупреждение рисков в рамках СВК осуществляются посредством применения следующих процедур:

- разграничение полномочий и обязанностей между сотрудниками в соответствии с их квалификацией, образованием, практическим опытом;

- контроль фактического наличия объектов и их физического состояниями (проведение инвентаризаций, охрана);

- контроль работы компьютерных информационных систем (проверка обновлений, разграничение доступа к базам данных для различных категорий работников);

- надзор, обеспечивающий оценку достижения поставленных целей или показателей (контроль исполнения бизнес-планов, бюджетов, смет, а также анализ причин отклонений и разработка программ по совершенствованию результатов с учетом возникших ошибок);

- документальное оформление фактов и итогов хозяйственной жизни (составление первичных и отчетных документов).

Следует отметить, что в современной управленческой практике ключевым фрактором оценки рисков является информация разного рода (экономическая, фринансовая, статистическая). При этом наибольшее значение приобретает не столько информация макро- и мезосреды организации (о показателях ВВП, темпах инфляции, социально-демографических фракторах и т. п.), сколько внутренние данные, или информация микроуровня (экономико-финансовые параметры самой компании и т. д.). Особая важность подобных сведений обусловлена следующим:

- во-первых, совершенное владение внутренней информацией предприятия способствует выявлению скрытых резервов улучшения фринансово-экономических элементов развития, наращиванию темпов экономического роста;

- во-вторых, она позволяет осуществлять грамотное текущее управление финансовым, производственным и человеческим капиталом.

В данном аспекте документ в качестве основного носителя сведений о деятельности организации можно рассматривать не просто как способ коммуникации, но и как один из основополагающих элементов функционирования системы внутреннего контроля.

Как уже отмечено, исходным компонентом СВК выступает контрольная среда (совокупность норм, правил, стандартов, законодательных и нормативно-правовых актов, регулирующих порядок работы с документами в компании). В целях грамотного и эффрективного документооборота в локальном нормативном акте, посвященном рассматриваемой системе (например, в положении об СВК (далее - Положение)), необходимо закрепить нормативно-правовые акты, на основании которых должна строиться соответствующая деятельность: федеральных законах «Об информации, информационных технологиях и о защите информации» от 27.07.2006 г. № 149-Ф3, «Об электронной подписи» от 06.04.2011 г. № 63-Ф3, ГОСТе Р 7.0.97-2016 «СИБИД. Организационно-распорядительная документация. Требования к оформлению документов», ГОСТе Р ИСО 15489-1-2007 «СИБИД. Управление документами. Общие требования».

Также в Положении должны быть прописаны основополагающие правила работы с документами. Помимо общеизвестных принципов (своевременности, однократности регистрации, минимального времени обработки) необходимо сформулировать еще один, важный с точки зрения оценки рисков при осуществлении внутреннего контроля, - так называемый «принцип максимума». Каждый документ должен быть рассмотрен с позиции использования в процессе оценки рисков: содержит ли он информацию, необходимую для изучения микро- и макросреды, и может ли он быть полезным при финансово-экономическом анализе.

Данный принцип следует изучить более подробно. Документы в организации существуют в тесной взаимосвязи и для достижения управленческих целей фрормируют документооборот движение документов в компании с момента их создания или получения до завершения исполнения либо отправки [3]. Также нужно отметить, что путь документа не является унифицированным, а зависит от специфики управленческого процесса конкретной компании и утверждается графиком документооборота - схемой, которая описывает движение документов от создания или получения до передачи на хранение либо отправки.

Существуют различные варианты классификации документопотоков организации. Например, их можно разделить на следующие:

- внутренние (документы создаются и перемещаются на одном предприятии, в частности приказы по личному составу); говоры);

- входящие (документы, поступившие в компанию от контрагентов, - деловые письма, до- 
- исходящие (созданные в организации и направленные контрагентам - ответы на письма, отчетные формы и т. п.).

Целесообразно выделить документопотоки в зависимости от типа операций, которые сопровождает тот или иной документ. Однако если рассматривать его как один из ключевых элементов оценки и предупреждения риска, то все материалы можно подразделить на используемые и не используемые при принятии управленческих решений. Как правило, последние основаны на оценке производственной и финансовой ситуации предприятия, следовательно, документопотоки можно дифференцировать на применяемые и не применяемые в финансово-экономическом анализе. Например, среди кадровой документации приказы по личному составу относятся к документам, не задействованным в анализе, а табель учета рабочего времени - наоборот.

Основными направлениями экономической оценки в организации, как правило, являются следующие: анализ труда и заработной платы, определение эфффективности использования материалов и основных производственных фондов, исследование денежных потоков, установление финансовых результатов хозяйственной деятельности, изучение готовой продукции. В таблице 1 подробно рассмотрено, какие документы необходимы для принятия управленческих решений в процессе осуществления внутреннего контроля, а какие при этом не применяются.

\section{Таблица 1 - Документопоток в рамках экономического анализа}

\begin{tabular}{|c|c|c|}
\hline Направление & $\begin{array}{c}\text { Документы, используемые } \\
\text { при анализе }\end{array}$ & $\begin{array}{c}\text { Документы, не используемые } \\
\text { при анализе }\end{array}$ \\
\hline $\begin{array}{l}\text { Анализ труда и зара- } \\
\text { ботной платы }\end{array}$ & $\begin{array}{l}\text { Штатное расписание, табель учета рабо- } \\
\text { чего времени, расчетно-платежная ведо- } \\
\text { мость, лицевые счета и личные карточки } \\
\text { работников, записки-расчеты при предо- } \\
\text { ставлении отпуска и увольнении сотруд- } \\
\text { ников, график отпусков, отчеты о движе- } \\
\text { нии кадров }\end{array}$ & $\begin{array}{l}\text { Приказы по личному составу (о при- } \\
\text { еме на работу, переводе на другую } \\
\text { работу, увольнении, предоставле- } \\
\text { нии отпуска сотруднику и т. п.) }\end{array}$ \\
\hline $\begin{array}{l}\text { Анализ эффективно- } \\
\text { сти использования ма- } \\
\text { териалов }\end{array}$ & $\begin{array}{l}\text { Лимитно-заборные карты, требования- } \\
\text { накладные, карточки учета материалов, } \\
\text { акты на списание материалов, приемо- } \\
\text { сдаточные накладные, отчеты о движе- } \\
\text { нии товарно-материальных ценностей }\end{array}$ & $\begin{array}{l}\text { Доверенности на прием материа- } \\
\text { лов, акты о приемке материалов, } \\
\text { приходные ордера, акты инвентари- } \\
\text { зации товарно-материальных цен- } \\
\text { ностей }\end{array}$ \\
\hline $\begin{array}{l}\text { Анализ эффективно- } \\
\text { сти применения ос- } \\
\text { новных производ- } \\
\text { ственных фондов }\end{array}$ & $\begin{array}{l}\text { Карточки учета основных средств и нема- } \\
\text { териальных активов }\end{array}$ & $\begin{array}{l}\text { Акты о приеме-передаче основных } \\
\text { средств (зданий, групп объектов ос- } \\
\text { новных средств), накладные на } \\
\text { внутреннее перемещение объектов } \\
\text { основных средств, акты о списании } \\
\text { объектов основных средств, акты } \\
\text { инвентаризации основных средств }\end{array}$ \\
\hline $\begin{array}{l}\text { Анализ денежных пото- } \\
\text { ков и финансовых ре- } \\
\text { зультатов хозяйствен- } \\
\text { ной деятельности }\end{array}$ & $\begin{array}{l}\text { Справки-расчеты бухгалтера, банковские } \\
\text { выписки, отчеты кассира-операциониста, } \\
\text { кассовые книги, отчеты о прибыли и } \\
\text { убытках }\end{array}$ & $\begin{array}{l}\text { Платежные требования, платежные } \\
\text { поручения, инкассовые поручения, } \\
\text { приходные и расходные ордера }\end{array}$ \\
\hline $\begin{array}{l}\text { Анализ готовой про- } \\
\text { дукции }\end{array}$ & Товарно-материальные отчеты & $\begin{array}{l}\text { Товарные накладные, универсаль- } \\
\text { ные передаточные документы }\end{array}$ \\
\hline
\end{tabular}

Данный список не является исчерпывающим и может быть дополнен разными документами управленческого учета организации. Рассмотрев упомянутый перечень документов, следует выделить закономерности отбора материалов для анализа: документ должен содержать, во-первых, числовые значения, во-вторых, информацию о нескольких субъектах оценки (сводные регистры). Таким образом, более эффективно использовать отчетные фрормы и учетные регистры различного характера, чем первичные документы.

Формы документов, отобранных для анализа, должны быть закреплены в Положении о СВК. Также необходимо обеспечить бесперебойную передачу этих материалов в аналитический отдел (либо сотруднику, ответственному за проведение экономического анализа в организации) из разных структурных подразделений, отвечающих за тот или иной участок работы.

На рисунке 1 представлена схема документооборота, основанная на реализации финансовоэкономического анализа как главного фактора принятия управленческих решений в рамках осуществления контрольных функций. Данная модель отражает два параллельных документопотока: первичные документы (не используемые при оценке), проходящие этапы составления и передачи на архивное или текущее хранение; сводные регистры (применяемые в анализе), проходящие стадии составления, исследования на их основе, подготовки управленческой отчетности по его итогам, передачи отчетности лицам, ответственным за СВК и принятие управленческих решений. 


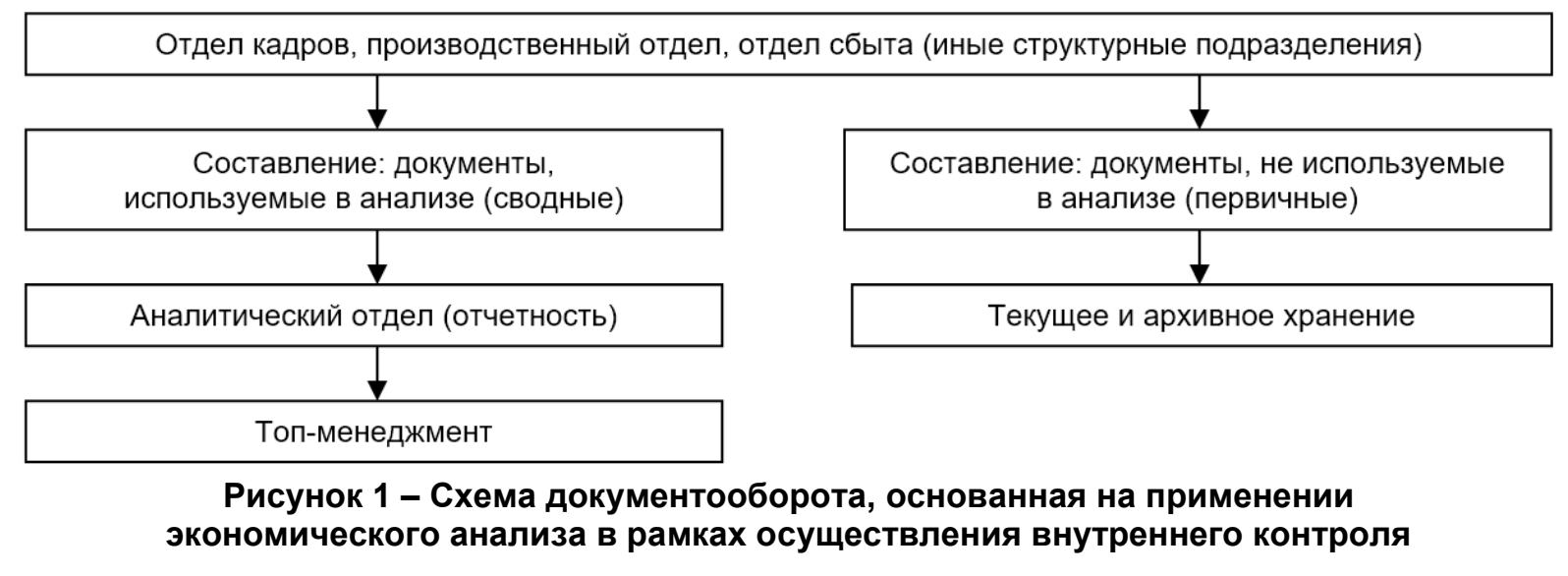

Следует отметить, что документы, используемые в анализе, должны содержать достоверные данные. В процессе работы на каждом этапе должна быть проведена оценка соответствия документов критериям достоверности (рисунок 2). Кроме того, при проверке разных типов материалов набор обязательных реквизитов и требования законодательства будут специфичными. Например, для кассового чека достаточно формального наличия реквизитов, в то время как при составлении трудового договора особое значение с юридической точки зрения приобретает его смысловая нагрузка.

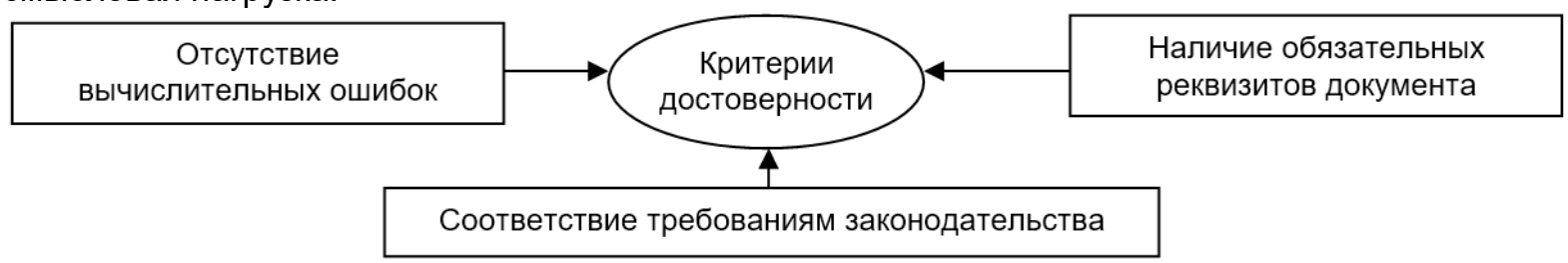

Рисунок 2 - Критерии достоверности документа

Для снижения вероятности возникновения вычислительных ошибок и неточностей иного рода рекомендуется применение электронных систем документооборота [4]. Следует признать, что организации находятся на различных этапах внедрения технологий электронного документооборота (далее - ЭДО), для большинства реальностью стал смешанный бумажно-электронный документооборот с постоянным возрастанием электронной составляющей и появлением новых организационно-технологических фрорм. На основании выборочного исследования государственных и негосударственных компаний (объектом послужила информация, размещенная на официальных сайтах) установлено, что преобладают смешанные делопроизводство и документооборот. Как подчеркивают Л. Весела и М. Радимерски, важно отличать действительный ЭДО от простой пересылки контрагентам скана документа, который затем распечатывается, подписывается, сканируется и отправляется обратно [5].

Хотя в российских компаниях активно используются программы автоматизации работы с документами группы 1C (Предприятие, Зарплата и Кадры), а также отправки отчетности в налоговые органы и Росстат, настройки совместимости систем, производимых разными операторами ЭДО, - достаточно редкое явление. Несмотря на высокую стоимость и трудоемкость разработки и внедрения программ, интегрирующих в единый комплекс все типы документации, применение подобного софта имеет ряд преимуществ, в том числе с точки зрения формирования эффективной системы внутреннего контроля, подразумевающей следующие элементы:

- контроль подписания документов и упрощенная процедура идентификации подписи (посредством электронной подписи);

- отсутствие необходимости дублирования одних и тех же материалов в электронном и печатном видах;

- повышение степени сохранности документов;

- возможность обзора и управления документопотоками структурных подразделений в едином комплексе.

Таким образом, для построения эффективной системы внутреннего контроля требуется реализация следующих задач:

- организация документооборота с применением электронных технологий, выстроенная в соответствии с требованиями экономического анализа как основного фактора оценки рисков и позволяющая объединить в рамках одной информационной системы все документопотоки предприятия; 
- построение работы с документацией согласно критериям достоверности и ценностного качества документа как исходной точки фрормирования системы внутреннего контроля.

\section{Ссылки и примечания:}

1. О бухгалтерском учете [Электронный ресурс] : федер. закон от 6 дек. 2011 г. № 402-Ф3 : в ред. от 23 мая 2016 г. Доступ из справ.-правовой системы «КонсультантПлюс».

2. Организация и осуществление экономическим субъектом внутреннего контроля совершаемых фактов хозяйственной жизни, ведения бухгалтерского учета и составления бухгалтерской (финансовой) отчетности [Электронный ресурс] : инфоормация Минфина России № П3-11/2013. Доступ из справ.-правовой системы «КонсультантПлюс».

3. ГОСТ Р 7.0.8-2013. СИБИД. Делопроизводство и архивное дело. Термины и определения. М., 2014.

4. Future paradigms of automated processing of business documents / M. Cristani, A. Bertolaso, S. Scannapieco, C. Tomazzoli // International Journal of Information Management. 2018. Vol. 40. June. P. 67-75. https://doi.org/10.1016/j.ijinfomgt.2018.01.010.

5. Veselá L., Radiměřský M. The development of electronic document exchange // Procedia Economics and Finance. 2014. Vol. 12. P. 743-751. https://doi.org/10.1016/s2212-5671(14)00401-8.

\section{References:}

Cristani, M, Bertolaso, A, Scannapieco, S, Tomazzoli, C. 2018, 'Future paradigms of automated processing of business documents', International Journal of Information Management, vol. 40, June, pp. 67-75. https://doi.org/10.1016/j.ijinfomgt.2018.01.010.

Veselá, L \& Radiměřský, M 2014, 'The development of electronic document exchange', Procedia Economics and Finance, vol. 12, pp. 743-751. https://doi.org/10.1016/s2212-5671(14)00401-8. 